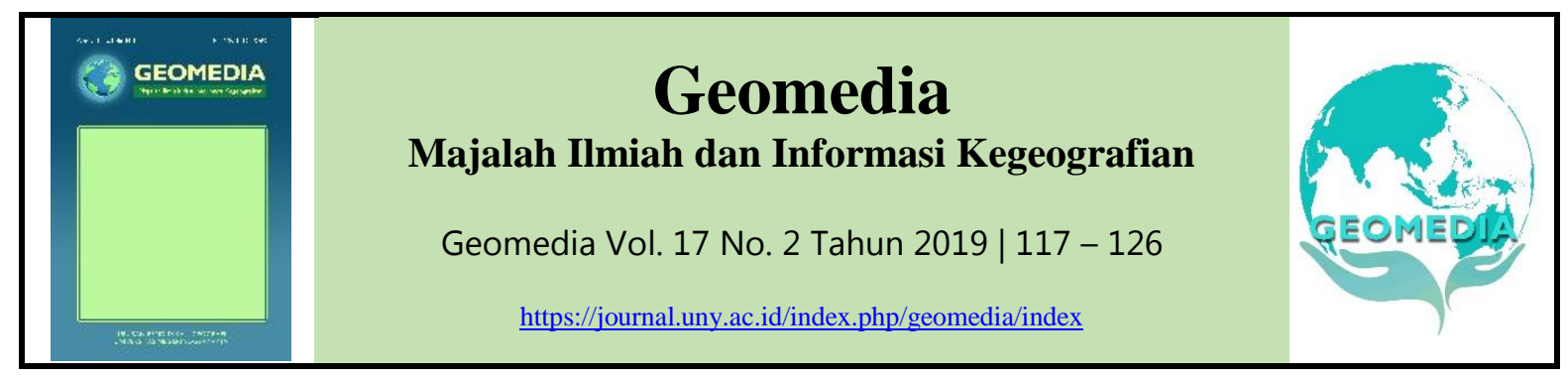

\title{
Video Interaktif Bencana Tanah Longsor; Media Sosialisasi Bahaya Tanah Longsor untuk Remaja
}

\author{
Rahma Hayati ${ }^{\text {a, }}{ }^{*}$, Nadya Amalia ${ }^{\text {b, } 2}$ \\ a Jurusan Geografi Fakultas Ilmu Sosial Universitas Negeri Semarang, Indonesia \\ b Praktisi Geografi, Kudus, Jawa Tengah, Indonesia \\ ${ }^{1}$ rahmahayati72@mail.unnes.ac.id *; 2nadnadnat@gmail.com \\ *korespondensi penulis
}

\begin{tabular}{ll}
\hline Informasi artikel \\
\hline Sejarah artikel & \\
Diterima $\quad:$ \\
Revisi $\quad:$ \\
Dipublikasikan : \\
\hline
\end{tabular}

\section{Kata kunci:}

Bencana tanah longsor

Video interaktif

Media sosialisasi

\begin{abstract}
A B S T R A K
Dusun Wetan Kali Desa Rahtawu merupakan daerah yang rentan terhadap longsor. Dibutuhkan peningkatan pengetahuan masyarakat tentang kesiapsiagaan bencana longsor. Sasaran dari penelitian ini adalah remaja dengan usia 13 - 19 tahun di Dusun Wetan Kali Desa Rahtawu. Tujuan dari penelitian ini adalah untuk mengetahui pengetahuan remaja tentang tanah longsor dan tanggapan remaja tentang sosialisasi tanah longsor dengan video interaktif. Sampel penelitian ini adalah 35 remaja. Metode pengumpulan data adalah metode dokumentasi, proses sosialisasi, tes instrumen, dan metode kuesioner. Teknik analisis data adalah teknik analisis persentase deskriptif dan perbandingan rata-rata pengetahuan menggunakan paired t-test. Terdapat peningkatan yang signifikan dalam pengetahuan tentang bencana tanah longsor pada kelompok remaja berusia 13 - 19 tahun setelah diberikan stimulus. Stimulus yang diberikan berupa video interaktif tentang bencana tanah longsor sebagai media sosialisasi. Kategori respons remaja kelompok 13 - 19 tahun adalah "sangat positif"
\end{abstract}

\section{A B S T R A C T}

\section{Keywords:}

Landslides Disaster

Interactive Video

Media Socialization
Wetan Kali Hamlet Rahtawu Village is vulnerable to landslides. It is need to increase people's knowledge about preparedness to landslides disaster. Target of this study is group of teenagers in range 13-19 years in Wetan Kali Hamlet, Rahtawu Village. The purpose of this study was to find out the knowledge of teenager about landslides and find out the teenager's response about the socialization of landslides with interactive videos. The research sample was 35 teenagers. Data collection methods were documentation methods, socialization processes, instrument tests, and questionnaire methods. The data analysis techniques were descriptive percentage data analysis techniques and comparison of the average knowledge using paired t-test. There is an increase significantly in knowledge about landslide disasters in the 13-19 year old teenager group, after being given a stimulus. The stimulus is socializing landslide disasters using interactive video as a media socialization. The category of response teenager group 13-19 years old is "Very Positive". 


\section{Pendahuluan}

Bencana alam semakin meningkat tiap tahunnya, baik yang disebabkan oleh proses alam maupun yang disebabkan oleh aktivitas manusia. Salah satunya adalah bencana tanah longsor yang sering terjadi di beberapa wilayah di Indonesia. Memasuki musim penghujan ancaman bencana ini semakin meningkat. Tanah longsor berubah menjadi bencana alam manakala kejadian tersebut menimbulkan korban baik berupa korban jiwa maupun kerugian harta benda dan hasil budaya manusia seperti bangunan rumah, fasilitas umum, dan lahan pertanian. Kerusakan-kerusakan tersebut secara tidak langsung melumpuhkan kegiatan pembangunan dan aktivitas ekonomi di daerah bencana dan sekitarnya (Suranto, 2008; Hardiyatmo, 2006). Banyak faktor yang mempengaruhi terjadinya bencana tanah longsor menjelaskan seperti kondisi geologi, hidrologi, topografi, iklim, dan perubahan cuaca dapat mempengaruhi stabilitas lereng yang mengakibatkan terjadinya longsoran. Longsoran jarang terjadi oleh satu sebab saja (Hardiyatmo, 2006).

Kabupaten Kudus adalah salah satu kabupaten di Jawa Tengah yang mempunyai beberapa kecamatan yang berpotensi terjadi bencana tanah longsor baik dalam tingkatan rawan bencana maupun cukup berbahaya. Salah satu kecamatan yang rawan terjadi bencana tanah longsor yaitu Kecamatan Gebog, dimana di kecamatan tersebut terdapat beberapa desa yang rawan terjadi bencana tanah longsor. Desa Rahtawu merupakan salah satu desa rawan bencana tanah longsor.

Selama beberapa tahun terakhir sering terjadi bencana tanah longsor di Desa Rahtawu Kecamatan Gebog, dan bencana tanah longsor terakhir terjadi pada tahun 2011. Kejadian tersebut menyebabkan rumah beberapa warga mengalami kerusakan, kerugian materi dan rusaknya fasilitas umum. Wilayah di Desa Rahtawu yang mengalami bencana tanah longsor tahun 2011 adalah Dusun Wetan Kali dan Dusun Semliro. Bekas dari lereng yang mengalami tanah longsor masih dapat dilihat sampai sekarang. Kondisi topografi Desa
Rahtawu yang berbukit-bukit dan berada di lereng pegunungan menyebabkan bencana tanah longsor sering terjadi di Desa Rahtawu, baik yang merupakan longsoran kecil sampai longsoran besar. Pada saat musim penghujan datang, masyarakat harus siap siaga dengan datangnya longsor yang tidak dapat diketahui secara pasti.

Tindakan dalam upaya kesiapsiagaan masyarakat terhadap bencana tanah longsor sudah dilakukan, dengan tujuan untuk menangani dan menanggulangi masalah bencana tanah longsor yang sering terjadi di Desa Rahtawu. Tindakan tersebut dilakukan untuk mengurangi korban jiwa, harta benda dan kerusakan fasilitas umum. Karena masyarakat harus siap akan terjadinya kejadian tanah longsor yang dapat menimbun serta memutus akses jalan utama menuju Desa Rahtawu dan dusun-dusun sekitar.

Pada saat terjadi bencana tanah longsor masyarakat Desa Rahtawu turut aktif dan gotong royong dalam menghadapi bencana. Dalam hal penanggulangan bencana, masyarakat merupakan pihak yang paling rentan menjadi korban dari bencana. Kerentanan tersebut dapat terjadi karena beberapa hal seperti kurangnya pengetahuan masyarakat tentang bencana alam, mitigasi bencana, rehabilitasi masyarakat pasca bencana, dan perhatian dari pemerintah. Tindakan kesiapsiagaan sangat penting diberikan lebih dini kepada masyarakat, terutama kepada remaja. Sebab pada usia remaja, seseorang sudah dapat berpikir secara abstrak, serta sudah mampu memikirkan sesuatu yang akan atau mungkin terjadi dari suatu sebab saat ini (Desmita, 2013).

Salah satu tindakan yang dapat dilakukan dalam kesiapsiagaan menghadapi bencana adalah sosialisasi. Menurut Soerjono Soekanto (dalam Nurdianti, 2014) sosialisasi diartikan secara luas sebagai suatu proses dimana masyarakat dididik untuk mengenal, memahami, mentaati, menghargai, dan menghayati norma-norma dan nilai-nilai yang berlaku di dalam masyarakat. Sosialisasi dapat berlangsung baik secara tatap muka, namun juga bisa dilakukan dengan jarak jauh melalui sarana, seperti media ataupun surat, 
dan juga dapat berlangsung secara formal, dan informal, dan secara sengaja maupun tidak sengaja. Sosialisasi pada penelitian ini dilakukan untuk meningkatkan pengetahuan remaja tentang bencana tanah longsor. Menurut Notoatmodjo (dalam Wibowo, 2017) pengetahuan merupakan hasil tahu dan ini terjadi setelah orang melakukan penginderaan terhadap suatu objek tertentu. Sebagian besar pengetahuan manusia di peroleh melalui mata dan telinga. Pengetahuan adalah domain yang sangat penting bagi terbentuknya tindakan seseorang, sehingga perilaku yang didasari oleh pengetahuan akan lebih langgeng dari pada perilaku yang tidak didasari oleh pengetahuan.

Sosialisasi dalam penelitian ini dilakukan pada remaja di Dusun Wetan Kali karena dusun tersebut merupakan salah satu dusun di Desa Rahtawu yang rawan akan terjadinya tanah longsor dan pernah terjadi bencana tanah longsor pada tahun 2011. Tindakan sosialisasi tentang bencana tanah longsor kepada remaja tersebut dapat dilakukan dengan menggunakan media. Media merupakan alat bantu yang digunakan untuk menunjang pengetahuan dan pemahaman manusia dalam mempelajari suatu hal. Media berasal dari bahasa Latin dan merupakan bentuk jamak dari kata medium yang secara harfiah berarti perantara atau pengantar, pengantar pesan dari pengirim ke penerima pesan (Sadiman,dkk, 2009).

Sosialisasi dalam penelitian ini mengunakan video interaktif sebagai media dalam upaya meningkatkan pengetahuan remaja, dimana dalam media ini terdiri dari teks, gambar, video, dan animasi yang menggambarkan dan menjelaskan tentang bencana tanah longsor. Penggunaan media video interaktif diharapkan kelompok remaja Dusun Wetan Kali dapat lebih paham tentang bencana tanah longor dan dapat memahami materi dengan mudah.
Penelitian ini bertujuan untuk mengetahui: (1) Pengetahuan remaja Dusun Wetan Kali tentang bencana tanah longsor, (2) Respon remaja tentang sosialisasi bencana tanah longsor menggunakan media video interaktif.

\section{Metode}

Populasi pada penelitian ini adalah remaja usia 13-19 tahun di Dusun Wetan Kali Desa Rahtawu sejumlah 137 orang. Sampel penelitian untuk proses sosialisasi adalah $25 \%$ dari jumlah populasi, diambil secara purposive random sampling. Metode pengambilan data yang digunakan dalam penelitian ini adalah metode dokumentasi, proses sosialisasi, intrument tes, dan metode angket. Data yang telah diperoleh melalui proses sosialisasi, instumen tes, dan metode angket dianalisis sesuai dengan masing-masing variabel penelitian. Teknik analisis data yang digunakan dalam penelitian ini adalah deskriptif persentase dan uji perbandingan rata-rata pengetahuan dengan menggunakan uji paired ttest.

\section{Hasil dan pembahasan}

\section{Gambaran Umum Lokasi dan Obyek Penelitian}

Penelitian dilakukan di Dusun Wetan Kali yang merupakan salah satu dusun di Desa Rahtawu. Secara adminstratif di sebelah timur yang berbatasan dengan Dusun Semliro (sebelah utara), Desa Ternadi (sebelah timur), Dusun Krajan (sebelah selatan), dan Dusun Gringsir (sebelah barat). Dusun Wetan Kali memiliki topografi yang berbukit-bukit dan terdapat beberapa sungai yang mengaliri wilayah Dusun Wetan Kali tersebut. Dusun Wetan Kali terbagi menjadi 8 RT (Rukun Tetangga) dan merupakan dusun dengan jumlah RT terbanyak di Desa Rahtawu. Lokasi penelitian ditunjukkan oleh Gambar 1. 


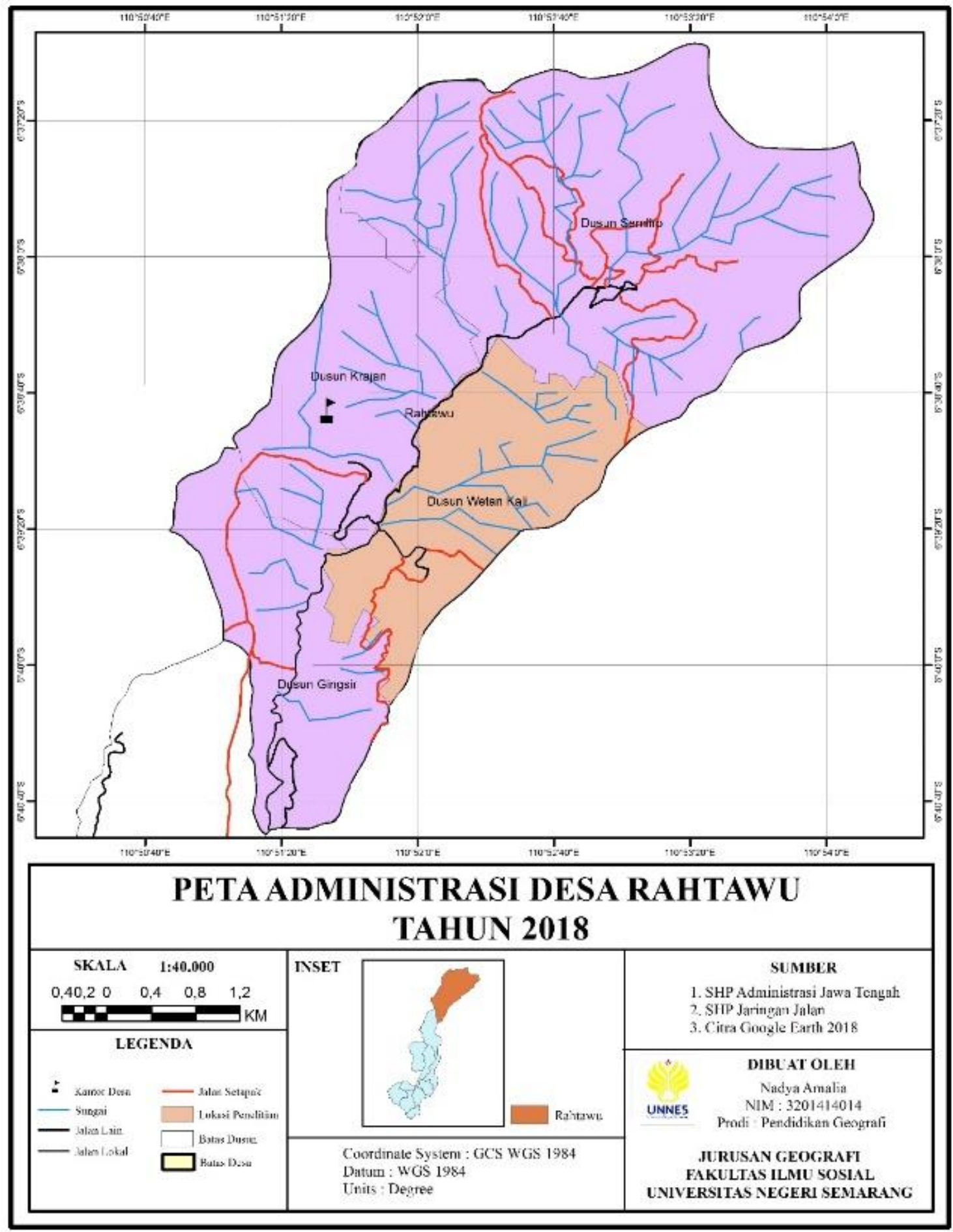

Gambar 1. Peta Lokasi Penelitian

\section{Kejadian Bencana Tanah Longsor di Desa Rahtawu}

Kejadian tanah longsor yang pernah terjadi di Kabupaten Kudus salah satunya adalah di daerah Desa Rahtawu. Di Desa Rahtawu setiap datang musim penghujan sering terjadi tanah longsor, baik di tebing sungai, tebing jalan, maupun lereng-lereng ataupun tebing-tebing bukit yang berada di sekitar desa. Berdasarkan tulisan Widjanarko (dalam Riani, 2013) di Desa Rahtawu pernah terjadi bencana besar yang terjadi pada tahun 2006. Bencana tersebut diakibatkan oleh meluapnya Kali Gelis yang melintasi Dusun Semliro di Desa Rahtawu. 
Sedangkan berdasarkan data dari Badan Penanggulangan Bencana Daerah Kabupaten Kudus (2010) pada bulan Januari dan Pebruari 2008, terjadi gerakan tanah lagi yang menyebabkan satu rumah di dusun Semliro dan tujuh rumah di Dusun Wetan Kali rusak total, 47 rumah rusak ringan.

Bukti bahwa pernah terjadi tanah longsor masih dapat dilihat di sekitar dusun tersebut. Sisa cekungan pada tanah yang diakibatkan dari gerakan tanah tampak masih jelas dan berada tepat di belakang Dusun Wetan Kali. Tabel 1 berikut ini menunjukkan daftar beberapa kejadian bencana tanah longsor di Desa Rahtawu.
Tabel 1. Kejadian Bencana Tanah Longsor di Desa Rahtawu

\begin{tabular}{lll}
\hline No & Waktu Kejadian & Keterangan \\
\hline 1 & Maret (2006) & Dusun Semliro \\
2 & Januari dan & Dusun Semliro, Dusun \\
& Februari (2008) & Wetan Kali \\
3 & Februari (2011) & $\begin{array}{l}\text { Dusun Semliro dan } \\
\text { Dusun Wetan Kali }\end{array}$ \\
4 & Januari (2015) & Dusun Semliro \\
5 & Desember (2015) & Dusun Semliro \\
6 & Maret (2017) & Dusun Semliro, Dusun \\
& & Krajan \\
\hline
\end{tabular}

Sumber: Data penelitian, 2018

Desa Rahtawu merupakan desa yang rawan bencana tanah longsor. Sebagian besar wilayah desa merupakan area rawan bencana tanah longsor (Gambar 2).

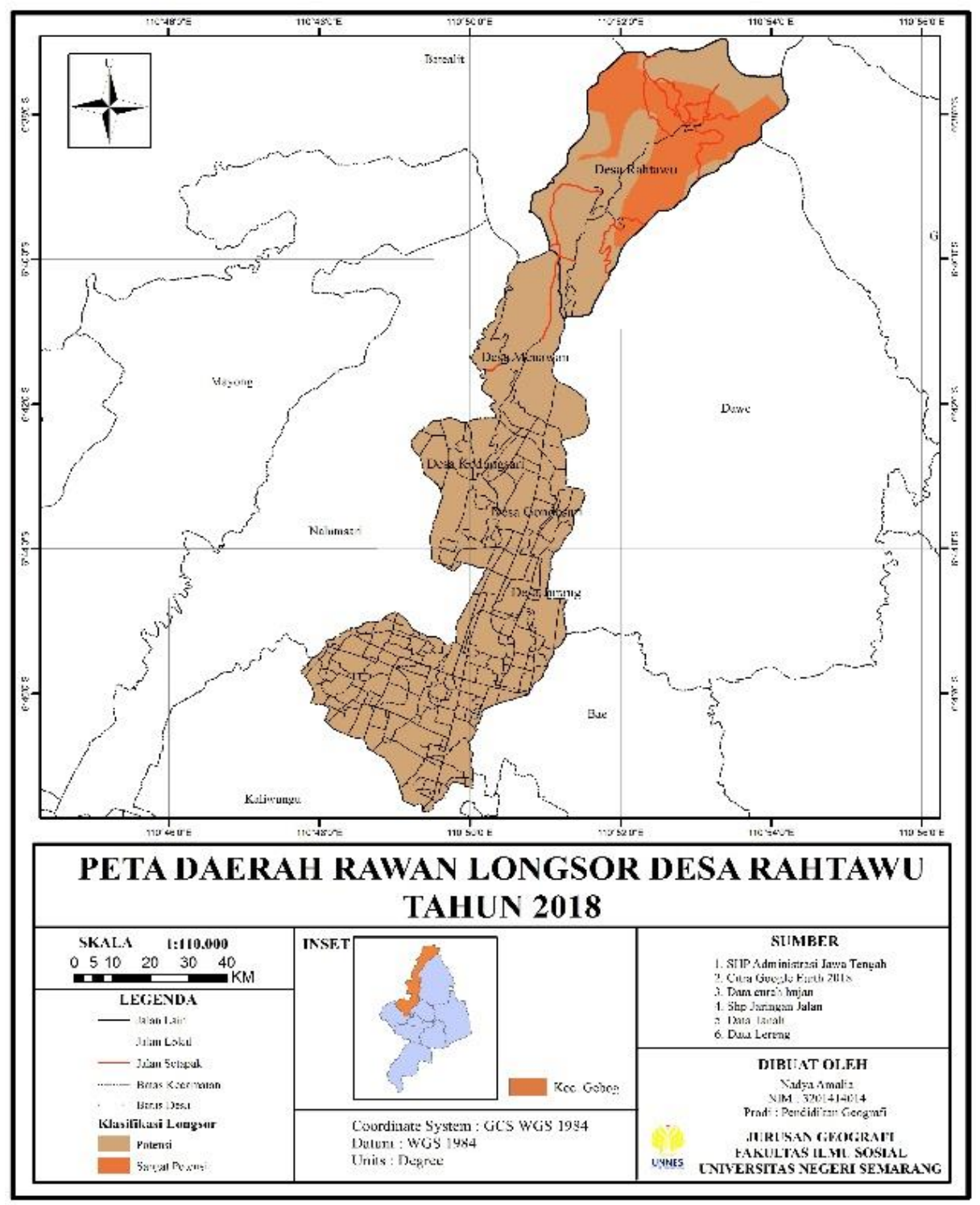

Gambar 2. Peta Daerah Rawan Longsor Desa Rahtawu Tahun 2018 


\section{Keadaan Demografi Dusun Wetan Kali}

Dusun Wetan Kali memiliki jumlah penduduk sebanyak 1.577 jiwa dengan komposisi penduduk ditunjukkan oleh Tabel 2.

Tabel 2. Jumlah Penduduk Dusun Wetan Kali Menurut Kelompok Umur

\begin{tabular}{lll}
\hline & Kelompok Umur & Jumlah (Jiwa) \\
No & & \\
\hline 1 & $0-7$ & 85 \\
2 & $8-14$ & 140 \\
3 & $15-21$ & 147 \\
4 & $22-28$ & 164 \\
5 & $29-35$ & 196 \\
6 & $36-42$ & 204 \\
7 & $43-49$ & 184 \\
8 & $50-56$ & 146 \\
9 & $57-63$ & 148 \\
10 & $>64$ & 163 \\
\hline Jumlah & $\mathbf{1 5 7 7}$ \\
\hline
\end{tabular}

Sumber: Data Penelitian, 2018

Di Dusun Wetan kali terdapat penduduk usia remaja antara 13-19 tahun sebanyak 137 jiwa. Persebaran penduduk usia remaja 13-19 tahun Dusun Wetan Kali ditunjukkan oleh Tabel 3.

Tabel 3. Penduduk Usia Remaja 13-19 Tahun Dusun Wetan Kali

\begin{tabular}{|c|c|c|c|c|}
\hline \multirow[t]{2}{*}{ No } & \multirow[t]{2}{*}{ RT/RW } & \multicolumn{3}{|c|}{$\begin{array}{l}\text { Penduduk Usia 13-19 } \\
\text { Tahun }\end{array}$} \\
\hline & & $\mathbf{L}$ & $\mathbf{P}$ & Jumlah \\
\hline 1 & RT1/RW2 & 11 & 9 & 20 \\
\hline 2 & RT2/RW2 & 11 & 8 & 19 \\
\hline 3 & RT3/RW2 & 4 & 3 & 7 \\
\hline 4 & RT4/RW2 & 5 & 10 & 15 \\
\hline 5 & RT5/RW2 & 7 & 12 & 19 \\
\hline 6 & RT6/RW2 & 16 & 10 & 26 \\
\hline 7 & RT7/RW2 & 11 & 6 & 17 \\
\hline 8 & RT8/RW2 & 7 & 7 & 14 \\
\hline \multicolumn{2}{|c|}{ Jumlah } & 72 & 65 & 137 \\
\hline
\end{tabular}

Sumber : Data Penelitian, 2018

Selanjutnya, dari penduduk usia remaja 13-19 tahun di Dusun Wetan Kali diambil sampel secara proporsional di semua wilayah RT. Tabel 4 menunjukkan jumlah sampel yang diambil dari masing-masing RT.
Tabel 4. Sampel Penduduk Usia Remaja 13-19 Tahun Berdasarkan Tempat Tinggal

\begin{tabular}{llll}
\hline No & RT/RW & $\begin{array}{l}\text { Penduduk } \\
\text { Usia 13-19 } \\
\text { Tahun }\end{array}$ & Sampel \\
\hline 1 & RT1/RW2 & 20 & 6 \\
2 & RT2/RW2 & 19 & 4 \\
3 & RT3/RW2 & 7 & 2 \\
4 & RT4/RW2 & 15 & 3 \\
5 & RT5/RW2 & 19 & 5 \\
6 & RT6/RW2 & 26 & 8 \\
7 & RT7/RW2 & 17 & 4 \\
8 & RT8/RW2 & 14 & 3 \\
\hline Jumlah & $\mathbf{1 3 7}$ & $\mathbf{3 5}$ \\
\hline
\end{tabular}

Sumber : Data Penelitian, 2018

\section{Media Video Interaktif (sebagai media sosialisasi)}

Penelitian ini menggunakan media untuk melakukan sosialisasi bencana, yaitu dengan media video interaktif bencana tanah longsor. Video tersebut berisi penjelasan yang berkaitan dengan Desa Rahtawu dan penjelasan tentang bencana tanah longsor, kesiapsiagaan bencana tanah longsor dan mitigasi bencana tanah longsor, dimana beberapa video tersebut bersumber dari BNPB. Berikut ini merupakan rincian video yang digunakan sebagai media dalam sosialisasi bencana tanah longsor bagi remaja usia 13-19 tahun di Dusun Wetan Kali Desa Rahtawu Kecamatan Gebog Kabupaten Kudus.

\section{Pembukaan}

Sebagai pembuka diberikan penjelasan tentang Indonesia sebagai negara yang rawan akan bencana alam. Gambar 3 berikut merupakan ilustrasi bagian dari pembukaan video.

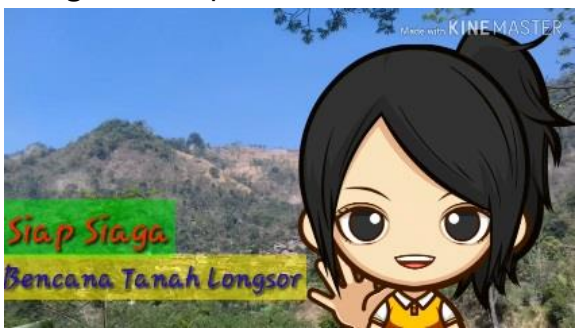

Gambar 3. Pembukaan Video

Bagian pembukaan juga menjelaskan tentang lokasi Desa Rahtawu yang terletak pada 
zona rawan longsor, sehingga diharapkan membuka pikiran responden untuk paham mengenai kerawanan desanya. Gambar 4 merupakan ilustrasi letak Lokasi Desa Rahtawu di dalam video.

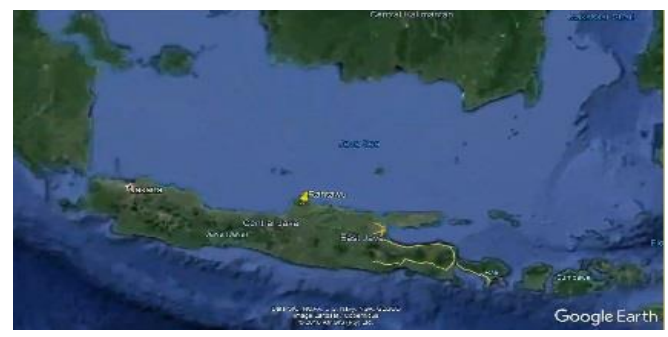

Gambar 4. Lokasi Desa Rahtawu

\section{Isi (Bencana Tanah Longsor di Rahtawu)}

Bagian berikutnya dari video interaktif adalah bagian isi. Bagian isi menjelaskan tentang bencana tanah longsor di Desa Rahtawu. Kejadiankejadian bencana tanah longsor, lokasi-lokasi kejadian tanah longsor, kerugian-kerugian dari bencana tanah longsor di Desa Rahtawu ditampilkan pada bagian ini. Ilustrasi kejadian tanah longsor ditunjukkan oleh Gambar 5 berikut.

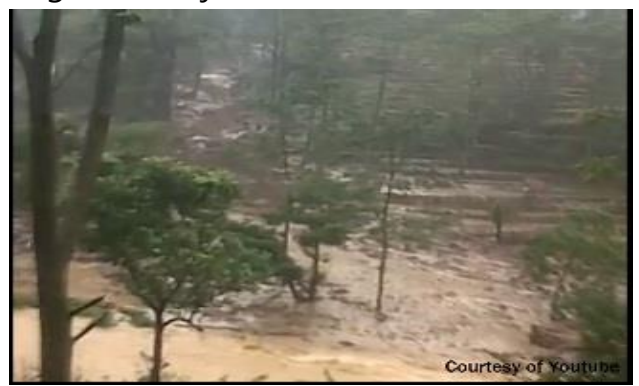

Gambar 5. Video Kejadian Tanah Longsor di

Desa Rahtawu

\section{Penjelasan (Penjelasan teoritik bencana tanah longsor)}

Bagian penjelasan menampilkan penjelasan tentang bencana tanah longsor, faktor-faktor yang mempengaruhi dan penyebab tanah longsor. Bagian ini juga menjelaskan tentang upaya yang harus dilakukan agar tidak terjadi bencana tanah longsor. Ilustrasi penjelasan tentang tanah longsor ditunjukkan oleh Gambar 6.

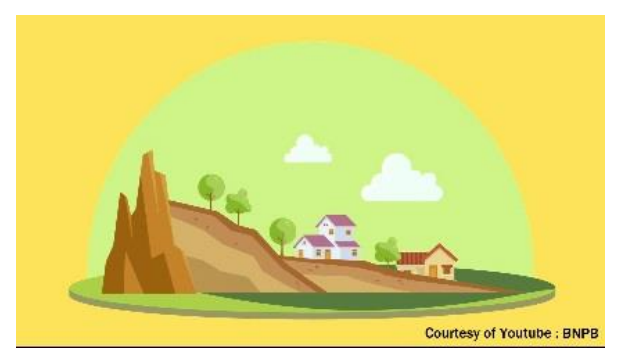

Gambar 6. Penjelasan tentang Tanah Longsor

\section{Kesiapsiagaan dan Mitigasi Bencana Tanah Longsor}

Bagian kesiapsiagaan dan mitigasi bencana tanah longsor menampilkan video animasi tentang mitigasi bencana tanah longsor yang dikeluarkan oleh Badan Nasional Penanggulangan Bencana. Bagian video ini memberikan pengetahuan tentang apa yang harus dilakukan sebelum, pada saat dan sesudah terjadi bencana. Gambar 8 berikut merupakan ilustrasi kesiapsiagaan dan mitigasi bencana tanah longsor dalam video.

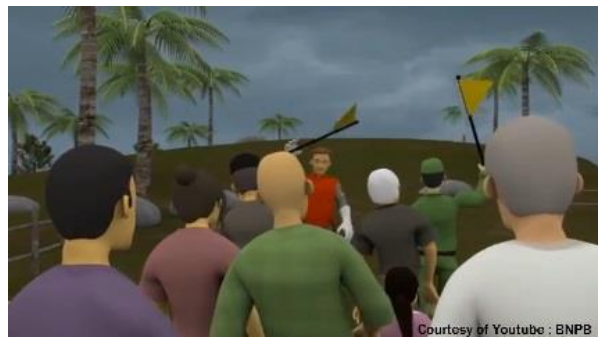

Gambar 8. Video Kesiapsiagaan dan Mitigasi Bencana Tanah Longsor

\section{Penutup}

Bagian penutup menampilkan ucapan terimakasih dari peneliti kepada para peserta sosialisasi bencana tanah longsor di Dusun Wetan Kali Desa Rahtawu.

\section{Pengetahuan Remaja Dusun Wetan Kali Tentang Bencana Tanah Longsor}

Langkah untuk mengetahui pengetahuan Remaja Dusun Wetan Kali tentang bencana tanah longsor terdapat dua pengukuran yaitu melalui pre-test dan post-test. Pre-test dilakukan sebelum stimulus yaitu sosialisasi tentang bencana tanah longsor melalui video interaktif. Hasil nilai pre-test dalam penelitian ini adalah tertinggi 93,1 dan terendah 67. Uji pre-test menunjukkan bahwa 
sebagian besar $(85,7 \%)$ termasuk dalam kriteria sangat baik (Tabel 5).

Tabel 5. Persentase Hasil Uji Pre-Test

\begin{tabular}{lll}
\hline Interval & Kriteria & Persentase \\
\hline $0 \%-25 \%$ & Kurang Baik & $0 \%$ \\
$26 \%-50 \%$ & Cukup Baik & $0 \%$ \\
$51 \%-75 \%$ & Baik & $14,3 \%$ \\
$76 \%-100 \%$ & Sangat Baik & $85,7 \%$ \\
\hline Jumlah & & $100 \%$ \\
\hline Rata-Rata & & $82,7 \%$ \\
\hline
\end{tabular}

Sumber : Data primer 2018

Stimulasi dalam penelitian ini adalah sosialisasi tentang bencana tanah longsor dengan menggunakan media video interaktif. Hasil nilai dari post-test yang didapatkan setelah remaja diberikan stimulus menunjukkan bahwa nilai tertinggi dari post-test yaitu 100 dan nilai terendah adalah 82,8. Berdasarkan pencapaian terhadap nilai maksimal, maka hasil uji post-test (100\%) termasuk dalam kriteria sangat baik ditunjukkan oleh Tabel 6.

Tabel 6. Persentase Hasil Uji Post-Test

\begin{tabular}{lll}
\hline Interval & Kriteria & Persentase \\
\hline $0 \%-25 \%$ & Kurang Baik & $0 \%$ \\
$26 \%-50 \%$ & Cukup Baik & $0 \%$ \\
$51 \%-75 \%$ & Baik & $0 \%$ \\
$76 \%-100 \%$ & Sangat Baik & $100 \%$ \\
\hline Jumlah & & $100 \%$ \\
\hline Rata-Rata & & $92,7 \%$ \\
\hline
\end{tabular}

Sumber: Data Penelitian, 2018

Selanjutnya dari data hasil pre-test dan posttest tersebut kemudian diolah untuk mengetahui perbandingan rata-rata antara nilai pre-test dan nilai post-test. Proses yang dilakukan meliputi uji normalitas, uji homogenitas, dan uji perbandingan pengetahuan dengan uji paired T-test.

Uji normalitas data dilakukan dengan bantuan SPSS 16.0 Kolmogorov-Smirnov. Setelah dianalisis diperoleh hasil bahwa nilai signifikansi pre-test sebesar 0,062 dan nilai signifikansi posttest sebesar 0,095 yang artinya data tersebut berdistribusi normal karena hasil nilai signifikansi $>0,05$.

Uji homogenitas dalam penelitian ini menggunakan SPSS 16.0 dengan analisis Levene Statistic. Dari hasil analisis tersebut diperoleh hasil nilai signifikansi hitungnya adalah 0,019. Sehingga dapat disimpulkan bahwa hasil pre-test dan post-test bersifat heterogen (tidak sama) karena nilai signifikansi $>0,05$.

Uji perbandingan rata-rata pengetahuan remaja antara nilai pre-test dan post-test dianalisis menggunakan Uji Paired T-Test pada SPSS. Berdasarkan hasil analisis uji paired t-test diperoleh nilai rata-rata hasil pre-test adalah 82,68 sedangkan untuk nilai rata-rata hasil posttest adalah 92,73 . Dan hasil nilai signifikansi 0,000 $<0,005$. Dari nilai tersebut terdapat perbedaan yang signifikan.antara nilai pre-test dan nilai post-test.

\section{Respon Remaja Tentang Sosialisasi Bencana Tanah Longsor Melalui Video Interaktif}

Hasil uji angket respon remaja menunjukkan bahwa dari 12 butir soal yang ada dengan total responden 35 orang. Skor maksimal yang mungkin (semua jawaban YA) adalah 12 . Skor minimal yang mungkin (semua jawaban TIDAK) adalah 0. Hasil uji respon menunjukkan bahwa nilai respon rata-rata dari 33 responden mencapai $94,05 \%$ dari nilai skor maksimal. Ratarata skor tersebut masuk dalam kategori respon "Sangat Positif". Berdasarkan hasil persentase pencapaian terhadap skor maksimal tersebut dapat disimpulkan bahwa kegiatan sosialisasi tentang bencana tanah longsor melalui media video interaktif sangat cocok diterapkan kepada remaja usia 13-19 tahun di Dusun Wetan Kali sebagai sumber pengetahuan tentang bencana tanah longsor.

Berdasarkan hasil penelitian diperoleh perbedaan nilai yang signifikan antara pengetahuan sebelum dilakukan sosialisasi dan sesudah sosialisasi dengan menggunakan media video interaktif. Remaja di Dusun Wetan Kali memiliki kemampuan awal atau pengetahuan awal tentang bencana tanah longsor cukup baik. Seperti diungkapkan oleh Andari (2012) bahwa kemampuan awal siswa memberikan pengaruh yang berbeda terhadap hasil belajar. Remaja di 
Desa Rahtawu jarang mendapatkan sosialisasi mengenai bencana tanah longsor, namun mereka telah mendapatkan pengetahuan tentang bencana tanah longsor tersebut dari keluarga, sekolah, maupun media massa. Pengetahuan dari berbagai sumber tersebut yang membuat mereka memiliki pengetahuan awal yang tinggi.

Media video interaktif yang digunakan dalam kegiatan sosialisasi turut berpengaruh dalam peningkatan pengetahuan remaja Dusun Wetan Kali tentang bencana tanah longsor. Penggunaan media yang berbeda dari yang biasanya (pamflet, buku, gambar, dan lain-lain) menyebabkan rasa ingin tahu remaja bertambah. Media video interaktif merupakan media yang baru bagi remaja di Desa Tahrawu keterkaitannya dengan sosialisasi bencana. Hal tersebut membuat remaja lebih fokus dalam memperhatikan materi yang dijelaskan. Hal ini seperti pernyataan dari Purwono (2014) bahwa peranan media pembelajaran sangatlah penting dalam proses transformasi ilmu pengetahuan itu sendiri, karena media pembelajaran sangat penting untuk memotivasi siswa, memberikan pengalaman serta mempermudah siswa dalam memahami materi yang disampaikan.

Media yang digunakan dalam pembelajaran harus dipilih berdasarkan tujuan dari penelitian. Purwono (2014) menjelaskan bahwa penggunaan media yang tepat merupakan suatu alternatif untuk mengatasi rendahnya hasil belajar peserta didik. Pada saat dilakukan sosialisasi bencana tanah longsor, remaja mengikuti dengan baik kegiatan sosialisasi bencana tanah longsor melalui media video interaktif. Pada saat pemutaran video, para remaja memperhatikan dan mendengarkan dengan baik, sehingga mereka mendapatkan hasil nilai pengetahuan remaja (post-test) yang meningkat secara signifikan dibandingkan dengan hasil pre-test.

Respon dari peserta sosialisasi terhadap media yang digunakan sebagian besar masuk dalam kategori respon sangat posisitf. Media video interaktif menarik untuk digunakan sebagai media dalam sosialisasi kepada remaja sehingga remaja tidak merasa jenuh pada saat mengikuti kegiatan sosialisasi dan mereka dapat menyerap materi dengan optimal. Hal ini sejalan dengan pernyataan dari Haryoko (2009) bahwa media audio-visual dapat memperlancar pemahaman sehingga dapat mengoptimalkan kemampuan dan potensi.

Pada penelitian ini kegiatan sosialisasi mengenai bencana tanah longsor dengan menggunakan media video interaktif mampu meningkatkan pengetahuan remaja. Kegiatan sosialisasi dengan menggunakan media video interaktif cocok dan efektif digunakan dengan sasaran remaja di Desa Wetan Kali, Desa Rahtawu. Remaja Desa Rahtawu memberi respon yang tinggi terhadap penggunaan media video interaktif untuk sosialisasi bencana tanah longsor. Remaja lebih mudah memahami mengenai lokasi desa mereka yang sangat rentan terhadap bahaya bencana tanah longsor. Remaja juga merasa lebih memahami mengenai mitigasi bencana tanah longsor.

\section{Simpulan}

Berdasarkan hasil penelitian dan pembahasan dapat disimpulkan bahwa terdapat peningkatan pengetahuan remaja usia 13-19 tahun di Dusun Wetan Kali Desa Rahtawu yang sangat signifikan mengenai bencana tanah longsor, setelah diberikan stimulus berupa sosialisasi bencana tanah longsor dengan menggunakan media video interaktif dan terdapat respon sangat positif dari remaja usia 13-19 tahun di Dusun Wetan Kali Desa Rahtawu tentang sosialisasi bencana tanah longsor menggunakan video interaktif.

\section{Ucapan terima kasih}

Ucapan terima kasih disampaikan kepada berbagai pihak yang telah membantu dalam penelitian dan penyusunan artikel.

\section{Referensi}

Andari, T. (2012). Efektifitas pembelajaran matematika menggunakan pendekatan kontekstual terhadap prestasi belajar 
matematika ditinjau dari kemampuan awal siswa kelas $v$ sd se-kecamatan bangunrejo kabupaten lampung tengah. JIPM (Jurnal Ilmiah Pendidikan Matematika), 1(1). http://www.bpbdkuduskab.com/search/label LLongsor. (9 Sep. 2018)

Desmita. (2013). Psikologi Perkembangan. Bandung: PT. Remaja Rosdakarya

Hardiyatmo, H.C. (2006). Penanganan Tanah Longsor dan Erosi. Yogyakarta : UGM Press.

Haryoko, S. (2009). Efektivitas Pemanfaatan Media Audio-Visual Sebagai Alternatif Optimalisasi Model Pembelajaran. Jurnal Edukasi Elektro 1 (5): 1-10.

Kurniawati, E. (2016). Respon Mahasiswa Iain Kendari Terhadap Dakwah Jurnalisme Online'. Doctoral Dissertation. IAIN Kendari.

Nurdianti, S.R. (2014). Analisis Faktor-Faktor Hambatan Komunikasi Dalam Sosialisasi Program Keluarga Berencana Pada Masyarakat Kebon Agung-Samarinda. Dalam eJournal Ilmu Komunikasi (2): 145-159.

Purwono, J. (2014). Penggunaan media audiovisual pada mata pelajaran ilmu pengetahuan alam di Sekolah Menengah Pertama Negeri 1
Pacitan. Jurnal Teknologi Pendidikan dan Pembelajaran, 2(2).

Riani, M., Prabandiyani, S.., I., Munifatul. (2013). Pemetaan Kondisi Tanah dan Vegetasi Sebagai Upaya Mengurangi Terjadinya Bencana Gerakan Tanah di Desa Rahtawu Kecamatan Gebog Kabupaten Kudus. Dalam Prosiding Seminar Nasional Pengelolaan Sumberdaya Alam dan Lingkungan 2013. Semarang: Pasca Sarjana Universitas Diponegoro. ISBN 978-602-17001-1-2.

Sadiman, A.S., Rahardjo, R., Haryono, A., Rahardjito. (2009). Media Pendidikan: Pengertian, Pengembangan dan Pemanfaatannya. Jakarta: Rajawali Pers.

Suranto, J.P. (2008). Kajian Pemanfaatan Lahan Pada Daerah Rawan Bencana Tanah Longsor Di Gununglurah, Cilongok, Banyumas. Tesis. Semarang: Fakultas Teknik UNDIP.

Wibowo, H.E. (2017). Pemanfaatan Media AudioVisual (Video) Sebagai Upaya Meningkatkan Pengetahuan Remaja Tentang Gerhana Matahari Di Dusun Rejosari Desa Pranten Kecamatan Bawang Kabupaten Batang. Skripsi. Semarang: Jurusan Geografi FIS UNNES. 